\title{
NEOLOGISMOS NA IMPRENSA ESCRITA: A COBERTURA JORNALÍSTICA
}

\author{
Clebson Luiz de Brito (FALE - UFMG)
}

\section{Introdução}

O léxico de uma língua não é algo estático ou fechado. De fato, como aponta BIDERMAN (1978:139), ele "constitui um vasto universo de limites imprecisos e indefinidos" e constantemente se renova, por força de novas necessidades de nomeação ou como demonstração da criatividade lexical dos integrantes de uma comunidade lingüística. A esses itens que brotam imprimindo nova paisagem lexical às línguas, denominamos neologismos. Essa denominação não se refere, no entanto, a apenas um novo termo, uma palavra inédita, formada graças aos processos de formação de palavras do sistema morfológico da língua, mas também a um novo sentido atribuído a um termo já existente, fato relacionado ao caráter polissêmico das palavras, e a um termo recém-chegado de um outro sistema lingüístico.

De fato, há basicamente três processos pelos quais o léxico se renova. Os chamados neologismos formais são produtos resultantes do emprego de recursos oferecidos pela própria língua, a saber, as regras de formação de palavras, tanto por derivação, com o uso dos afixos, como por composição, quando se unem duas ou mais bases. A criação neológica pode dar-se também, grosso modo, por reciclagem de um item lexical, ao qual é associada uma nova significação. A essa atribuição de uma nova significação a um termo já existente, denominamos neologismo semântico. $\mathrm{O}$ léxico de uma língua pode, ainda, ampliar-se por meio de empréstimos quando, na interação entre comunidades lingüísticas, itens lexicais de uma língua passam a ser empregados em outra.

A invasão de novos itens lexicais ao léxico nem sempre é percebida, pois "não nos damos conta de que muitas vezes estas unidades com que formamos 
enunciados não estavam disponíveis para uso e foram formadas por nós mesmos" - BASÍLIO (1987:5). Quase sempre o neologismo ganha visibilidade quando atinge um grande número de integrantes de uma dada comunidade lingüística. Segundo ALVES (1994:06), "é através dos meios de comunicação em massa e de obras literárias que os neologismos recém-criados têm a oportunidade de serem conhecidos e eventualmente serem difundidos". Tendo em vista as observações de BASÍLIO (1987:5) e ALVES (1994:06), este artigo, como forma de apontar a constante renovação lexical do português, tem por objetivo reunir neologismos coletados no texto jornalístico.

Com efeito, circulam pela grande imprensa escrita novos termos, grande parte dos quais não integrará o léxico comum da comunidade lingüística e, portanto, não chegará a ser dicionarizada. Muitos neologismos são criados sem fins utilitaristas; apenas atendem à necessidade expressiva do momento. De fato, a escrita jornalística, sobretudo de colunistas e articulistas, é marcada pela constante criação neológica, cujos produtos estão carregados de ironia, sátira e bom humor, que não raro contribuem para a capacidade expressiva dos textos. Essa característica é particularmente marcante com relação à cobertura jornalística da política, contexto do qual foram retirados os neologismos presentes neste artigo.

É no contexto político, portanto, que este trabalho pretende confirmar o que dissemos nesta introdução. Para fazer isso, e fazê-lo de forma clara, optou-se por organizar este texto da seguinte forma: na seção 1, explicitam-se os procedimentos metodológicos utilizados; na seção 2, apresentam-se os neologismos, bem como a análise destes; na seção 3 , por sua vez, procede-se à realização de algumas considerações decorrentes da investigação.

\section{Metodologia}

Extraíram-se, como corpus demonstrativo da renovação lexical, 18 itens lexicais não dicionarizados, quer com relação à forma, no caso de neologismos formais,

\footnotetext{
${ }^{1} \mathrm{O}$ grifo é nosso.
} 
quer com relação à significação, no caso dos neologismos semânticos. Como o objetivo deste trabalho é, a partir de uma pequena amostragem de material neológico, apresentar alguns neologismos surgidos na imprensa, mais especificamente aqueles relacionados à criação na cobertura política, apenas um jornal foi utilizado na pesquisa: A Folha de São Paulo, jornal de circulação nacional.

Os dicionários usados na averiguação do caráter neológico dos itens arrolados foram FERREIRA (1999), conhecido como Aurélio, e HOUAISS (2001), visto que são os dois maiores e mais populares do Brasil.

Os neologismos analisados estão tais como encontrados no jornal e aparecem em negrito, para a melhor visualização no excerto. A contextualização é feita por meio do registro de todo o período do qual fazem parte ou, quando suficiente, de um fragmento deste, havendo nesse caso a indicação, pelo uso de reticências entre parênteses, de que parte foi omitida. Algumas observações extralingüísticas são feitas quando o contexto apenas não é capaz de explicitar o sentido da palavra e também quando são necessárias para a compreensão do caráter satírico da criação neológica.

\section{Análise do corpus}

Apresenta-se, nesta seção, o corpus de que lança mão este trabalho, bem como a análise dos itens lexicais que o compõem. É por meio da análise que se segue que se pretende confirmar não apenas a produtiva renovação lexical na cobertura política, como também que essa renovação funciona como um recurso expressivo.

28/03/2006 pág. A3.

"Lula passará para a história como alguém que procurou amordaçar a imprensa com uma tentativa de criação de um orwelliano conselho de jornalismo".

- Categoria gramatical / Gênero: Adjetivo masculino. 
- Observações extralingüísticas: Orwell refere-se a George Orwell, escritor inglês nascido na Índia em 1903 e autor de 1984, fábula que retrata um mundo dominado pelo socialismo stalinista que matinha o controle sobre tudo. Em 1984 há uma máquina estatal controlada pelo Big Brother, o Grande Irmão, que articulava os impressionantes recursos da propaganda com uma eficiente polícia da consciência, hábil em detectar e suprimir com rigor qualquer possibilidade de dissidência.

- Análise lingüística: Neologismo formal formado pelo substantivo próprio Orwell acrescido do sufixo -ano, formador de adjetivo.

24/04/2006 pág. A1.

"Do lado da oposição, PSDB e PFL parecem temer o aparecimento de mais conexões com o valerioduto ou ruralduto".

- Categoria gramatical / Gênero: Substantivos masculinos.

- Observações extralingüísticas: (1) As palavras estão relacionadas a um esquema de pagamento mensal, chamado mensalão, outro neologismo, em troca do voto de parlamentares, que teria sido montado durante o governo do Presidente Luiz Inácio Lula da Silva e que foi noticiado em 2005; (2) O empresário Marcos Valério e o Banco Rural estão relacionados ao que está relatado em (1). Por eles teria passado o dinheiro para o pagamento pelo voto de parlamentares.

- Análise lingüística: Valerioduto - Neologismo formal formado por composição por justaposição - Valério (Marcos Valério) + duto.

Ruralduto - Neologismo formal formado por composição por justaposição - Rural (Banco Rural) + duto.

29/03/2006 pág. A2.

"Mas nem Severino se deu à grotesqueria de xaxar no plenário".

- Categoria gramatical / Gênero: Substantivo feminino.

- Observação extralingüística: Comentário acerca da chamada dança da impunidade protagonizada pela deputada Ângela Moraes 
Guadagnin (PT-SP) por ocasião da absolvição do Deputado João Magno (PT-MG), acusado de receber o chamado mensalão, explicado no item anterior. Severino refere-se a Severino Cavalcante, ex-presidente da Câmara dos Deputados.

- Análise lingüística: Neologismo formal formado por derivação sufixal - grotesco + aria. Esta formação tem grande carga pejorativa.

05/04/2006 pág. A2.

“(...) que Lula acabe se saindo mal do mensalãogate, caseirogate e outros".

- Categoria gramatical / Gênero: Substantivos masculinos.

- Observação extralingüística: Os termos referem-se, respectivamente, ao mensalão, explicado em itens anteriores, e à quebra ilegal do sigilo bancário de um caseiro, cujo mandante seria o então Ministro da Fazenda, Antônio Palloci.

- Análise lingǘstica: Neologismos formais formados pelas bases mensalão e caseiro, acrescidas de gate, palavra de origem inglesa, que, embora signifique 'porta', tem sido usada como sufixo capaz de indicar a idéia de 'corrupção', graças ao notório escândalo americano de watergate.

05/04/2006 pág. A4.

“(...) empenha para delubizar o ex-Ministro Antônio Palocci”.

- Categoria gramatical: Verbo.

- Observação extralingǘstica: A base para formação desta palavra é Delúbio, que se refere a Delúbio Soares, tesoureiro do PT por ocasião do escândalo do mensalão.

- Análise lingüística: Neologismo formal formado pelo substantivo próprio Delúbio acrescido do sufixo verbal -izar. O verbo tem o significado de 'transformar em Delúbio', 'atribuir característica de Delúbio’. 
06/04/2006 pág. A2.

"O que parece proibido é informar sobre alternativas ao fla-flu imbecil entre PT e PSDB”.

- Categoria gramatical / Gênero: Substantivo masculino.

- Observação extralingüística: Comentário acerca da cobertura da corrida presidencial do ano de 2006.

- Análise lingüística: Neologismo formal formado por composição pela truncação ou abreviação de Flamengo e Fluminense, dois clubes de futebol do Brasil. No período acima, o sentido é 'enfrentamento', com idéia de 'polarização', no contexto da corrida presidencial, entre os partidos políticos apontados.

09/04/2006 pág. A2.

"A resposta é que o povo, povo-povo, ainda não se convenceu de que Lula é o culpado maior".

- Categoria gramatical / Gênero: Substantivo masculino.

- Análise lingüística: Neologismo formal formado pela reduplicação da base povo. O recurso indica que o povo em questão é 'a grande massa', aqueles que também são chamados, pejorativamente, de 'povão'.

10/04/2006 pág. A4.

"A ordem agora é avançar sobre a quebra de sigilo do caseiro e Paulo Okamotto, o "doador universal"”.

- Categoria gramatical / Gênero: Sintagma nominal masculino.

- Observação extralingüística: Recaiu sobre Paulo Okamotto, então Presidente do SEBRAE, a desconfiança por ter pagado as contas de Lula, então candidato à Presidência da República, e do seu filho.

- Análise lingüística: Neologismo semântico, que surge da mudança de contexto do sintagma, cuja acepção está relacionada à característica do sangue tipo $\mathrm{O}$, que aparece como subentrada de doador no HOUAISS (2001). Foi criado para satirizar as explicações 
dadas pelo então Presidente do SEBRAE, que alegou amizade como motivação para o pagamento das contas de Lula e de seu filho.

23/04/2006 pág. A4.

"O amigo-pagador (Paulo Okamotto) está na mira da CPI".

- Categoria gramatical / Gênero: Substantivo masculino.

- Análise lingüística: Neologismo formal formado por composição por justaposição - amigo + pagador. Está relacionado ao contexto do item anterior (doador universal) e, como ele, tem intenções claramente satíricas.

12/04/2006 pág. A2.

"É de lamentar que energia semelhante à despendida por Lula na expansão de seu programa-vedete não venha sendo empregada na racionalização da rede de proteção social do Estado”.

- Categoria gramatical / Gênero: Substantivo masculino.

- Análise lingüística: Neologismo formal formado por composição por justaposição - programa + vedete, cujo significado é 'o principal programa', 'o mais importante programa', 'o programa que mais chama a atenção.

12/04/2006 pág. A4.

"Em dezembro do ano passado, acusado de ser um 'engavetador', Souza (...)".

- Categoria gramatical: Verbo.

- Observação extralingüística: Souza refere-se a Antônio Fernando de Souza, Procurador-Geral da República.

- Análise lingüística: Neologismo formal formado pela base engavetar acrescida do produtivo sufixo -dor, formador de substantivo agentivo. Há uma carga pejorativa nesta formação, 
visto que denomina 'aquele que arquiva, que engaveta processos, que não permite investigação'.

16/04/2006 pág. A7.

“(...) que denunciou 40 integrantes da quadrilha-companheira que saqueou as arcas públicas".

- Observação extralingüística: Este neologismo guarda relação com o escândalo do mensalão, explicado em itens anteriores.

- Categoria gramatical / Gênero: Substantivo feminino.

- Análise lingüística: Neologismo formal formado por composição por justaposição - quadrilha + companheira. Companheira é, por metonímia, referência ao PT.

25/04/2006 pág. A11.

"Com a sutileza que a política merece e tão pouco recebe das lideranças do PSDB, do PT e de outros Zagueiros de várzea, a cúpula do PFL (...)".

- Categoria gramatical / Gênero: Sintagma nominal masculino.

- Análise lingǘstica: Neologismo formal formado pelo processo de formação sintagmática, à maneira de zagueiro de área e zagueiro de sobra, exemplos de formações que aparecem como subentrada de zagueiro no HOUAISS (2001). Há, para este sintagma, um sentido bem pejorativo ligado ao contexto do futebol: 'zagueiro de pouca habilidade'. No contexto contemplado pelo fragmento acima, o contexto político, o significado é 'parlamentar e/ou partido sem sutileza, sem habilidade no trato'.

26/04/2006 pág. A10.

"Nosso guia (Lula) tem razão quando critica o pessimismo compulsivo de seus adversários. Requenta a queixa de FFHH (Fernando Henrique Cardoso) diante dos "fracassomaníacos"”.'

- Categoria gramatical / Gênero: Substantivo masculino. 
- Análise lingüística: Neologismo formal formado por composição por justaposição - fracasso + maniaco.

02/05/2006 pág. A4.

"Impedido de voltar à Câmara, o mensaleiro-que-renunciou, Pedro Corrêa (PP), tentará eleger a família".

- Categoria gramatical / Gênero: Substantivo masculino.

- Observação extralingüística: O Deputado Pedro Corrêa, acusado de receber pagamento em troca do voto, no escândalo conhecido como mensalão, durante o governo Lula, renunciou ao mandato.

- Análise lingüística: Neologismo formal formado por composição por justaposição - mensaleiro + que + renunciou. Esta é uma composição sintagmática em que mensaleiro é o determinado e querenunciou, o determinante. Mensaleiro, uma das bases desta composição, também é um neologismo e nomeia todo aquele que teria recebido o chamado mensalão, já explicado em itens anteriores. Formações dessa natureza visam a chamar a atenção do leitor, por causarem estranhamento, e têm claramente caráter satírico.

09/05/2006 pág. A4.

"Além do bombardeio da oposição, o governo também sofreu ontem com o 'fogo amigo' do senador Eduardo Suplicy (PT-SP)".

- Categoria gramatical / Gênero: Sintagma nominal masculino.

- Observação extralingüística: Fogo amigo, expressão militar bastante empregada durante a invasão dos Estados Unidos ao Iraque, referese a ataques militares que acabam por atingir companheiros ou aliados. Essa lexia não é registrada pelos dicionários consultados.

- Análise lingüística: Neologismo formal formado pelo processo formação sintagmática, cujo significado é, no contexto militar, 'ataque desferido por aliados' e, no contexto político, contexto que envolve o período acima, 'ataque desferido por membros do mesmo partido ou por aliados políticos'.

Fonte: Jornal A Folha de São Paulo (todas). 


\section{Conclusão}

Os neologismos arrolados neste artigo dão-nos prova do caráter não estático do léxico. O acervo lexical expande-se, quer para atender a novas necessidades relacionadas à nomeação, quer para atender a fins estéticos. Desse fato, a imprensa escrita, devido ao uso de neologismos e devido ao alcance que consegue, é grande divulgadora; ela, ao veicular diversos neologismos, torna visível o fato de o léxico ser aberto.

Porém a imprensa escrita vai além; usa da possibilidade de ampliar o léxico, explora os limites imprecisos do léxico para dar maior expressividade aos seus textos. Essa característica mostrou-se evidente na cobertura política, contexto do qual se extraíram os neologismos deste trabalho. De fato, fica claro, a partir dos neologismos arrolados aqui, que os recursos morfológicos da língua e o caráter polissêmico das palavras são manipulados no texto jornalístico, em sintonia com o que diz ALVES (1994:86), "por razões estilísticas e, nesse caso, contribui para causar efeitos intencionais - estranhamento, ironia, cor local... - em uma mensagem".

Com efeito, a cobertura da política por parte da imprensa escrita é marcada pelo uso da criação neológica por razões estilísticas, capaz de gerar novos itens lexicais que retratam, que fotografam, que fazem a crônica do cenário político. É de lamentar que a criatividade, a busca pelo novo, a inventividade no cenário político, haja vista os significados dos neologismos apontados aqui, que indicam práticas há muito conhecidas pela população brasileira, resume-se apenas à criação neológica.

\section{Referências Bibliográficas}

ALVES, Ieda Maria. Neologismo: criação lexical. São Paulo: Ática, 1994;

BASÍLIO, Margarida. Teoria lexical. São Paulo: Ática, 1987;

BIDERMAN, Maria Tereza Camargo. Teoria lingüística: lingüística quantitativa e computacional. Rio de Janeiro: LTC, 1978; 
FERREIRA, A. B. de Holanda. Novo dicionário de língua portuguesa. Rio de Janeiro: Ed. Nova Fronteira, 1999;

HOUAISS, Antônio; VILLAR, Mauro; FRANCO, Francisco Manuel de Mello; INSTITUTO ANTÔNIO HOUAISS DE LEXICOGRAFIA. Dicionário Houaiss da lingua portuguesa. Rio de Janeiro: Objetiva, 2001;

ISQUERDO, Aparecida Negri \& KRIEGER, Maria da Graça (org.). As ciências do Léxico II: lexicologia, lexicografia, terminologia. Campo Grande, MS: Ed. UFMS, 2004;

ROCHA, Luiz Carlos de Assis. Estruturas morfológicas do Português. Belo Horizonte: Ed. UFMG, 1998 (Coleção Aprender). 